\title{
Robotics and transanal minimal invasive surgery (TAMIS): The "sweet spot" for robotics in colorectal surgery?
}

\author{
R. Hompes ${ }^{1}$
}

Received: 2 June 2015/Accepted: 2 June 2015/Published online: 25 June 2015

(C) Springer-Verlag Italia Srl 2015

The article by Atallah et al. [1] in this month's issue illustrates the possibilities and future for (robotic) transanal surgery. The senior authors have been at the forefront of some of the most recent and exciting innovations in colorectal surgery. In 2009, they reported on their early experience of using a single-port device through the anus with standard laparoscopic instrumentation and "coined" the term transanal minimal invasive surgery (TAMIS) [2]. Similar to transanal endoscopic microsurgery (TEM), the concept of TAMIS evolved out of necessity, but at a better time in surgical evolution. While TEM was developed by Buess in relative isolation from the later surge in minimal invasive approaches, TAMIS has evolved rapidly into an established technique that revolutionized the practice of many colorectal surgeons and was a real boost for manufacturers and surgical innovators in this field.

Since the inception of TAMIS, several changes have been made to optimize the technique and broaden indications, reflecting the stages described by the IDEAL framework-idea, development, exploration, assessment, and long-term study-for surgical innovation [3]. While "endoluminal TAMIS" fueled the initial development, it is currently the extraluminal approaches for TAMIS, in particular transanal total mesorectal excision (taTME), that are the catalyst for ongoing innovation.

Robotic transanal surgery is one of the developments which have arisen from the natural evolution of TAMIS. The potential advantages of robotic TAMIS include

R. Hompes

roelhompes@gmail.com

1 Department of Colorectal Surgery, Churchill Hospital, University Hospitals of Oxford, Old Road, Oxford OX3 7LE, UK excellent ergonomics, tremor elimination, motion scaling, and instruments with multiple degrees of freedom. All the above features are ideal for working in a confined space, where conflict between instruments and optics is otherwise common, and can hamper operative flow and accuracy. After initial cadaveric trials, the senior authors reported on the use of the da Vinci ${ }^{\circledR}$ surgical robot to perform TAMIS as an option for rectum-preserving excision of neoplasms [4]. The feasibility and safety of this approach have been confirmed in a cohort series $(n=16)$ from our group using the glove port as the transanal platform [5]. The investigation of the role for the robotic platform in "from below" extraluminal approach or taTME was the natural next step forward.

The uptake of minimal invasive approaches for rectal cancer has been slow, despite the obvious short-term benefits and apparent similar long-term outcomes. Mainly, the challenges of low pelvic dissection in the male narrow pelvis, associated with long operating times and a long learning curve, have tempered adaption rates [6].

The meticulous dissection that can be achieved from below while adhering to the concept of an oncological sound TME seems to have potential benefits in comparison with a pure minimal invasive approach from above.

The authors report retrospectively on the endoluminal (local excision rectal neoplasms and repair complex fistula) and extraluminal application (transanal total mesorectal excision) of robotic TAMIS.

While early developments of innovative surgical procedures have historically been reported as retrospective case series, this method does introduce bias and wastes opportunities to provide useful information to the reader. From the original description of TAMIS to the current cohort of robotic TAMIS, several procedural changes would have been made throughout to get to the point of the 
current setup. It would have been informative/interesting if the authors had reported details of all cases in sequence, with clear information about patient selection and modifications of setup to provide maximum clarity about changes in technique and patient outcomes over time. Explicit reporting of such modifications, in the prospective development study (PDS) format, is recommended by the IDEAL Collaboration and has clear advantages when presenting uncontrolled early study data from innovative procedures [7].

The IDEAL framework is based on the suggestion that surgical innovation and evaluation can and should evolve together in an ordered manner from concept, through exploration, to validation by randomized trials. It consists of 5 stages starting with a new procedure's first use in humans (stage 1). The development stage (2a) follows when the technique is rapidly modified to optimize the safety, efficiency, and ease of use for the new procedure. The exploration stage ( $2 b)$ begins when the technique is stable and these modifications cease. The purpose of stage $2 \mathrm{~b}$ is to expand use of the new technique, assess learning curves, and identify optimal outcome measures in preparation for a formal evaluation of the new technique in a randomized controlled trial in the assessment stage [3]. An overview from the authors in this format would truly give the readers an insight into the innovative pathway they have followed.

Certain people might question the added benefit of the robot, in particular given the financial implications, difficulties in docking, and the potential for significant clash of robotic arms in a confined space. However, the true value of this paper and the approach described lies within the proof of concept, and what lies ahead. The combination of evolving robotic technology and platforms for TAMIS could be the "sweet spot" for robotics in colorectal surgery.
Conflict of interest Roel Hompes is a regular faculty member for TAMIS courses organized by Applied Medical. This manuscript is the sole work and authorship of Mr. R. Hompes. This was not financially supported by any agency or person.

Ethical approval This article does not contain any studies with human participants performed by any of the authors.

Informed consent For this type of study formal consent is not required.

\section{References}

1. Atallah S, Martin-Perez B, Parra-Davila E et al (2015) Robotic transanal surgery for local excision of rectal neoplasia, transanal total mesorectal excision, and repair of complex fistulae: clinical experience with the first 18 cases at a single institution. Tech Coloproctol. doi:10.1007/s10151-015-1283-8

2. Atallah S, Albert M, Larach S (2010) Transanal minimally invasive surgery: a giant leap forward. Surg Endosc 24:2200-2205

3. McCulloch P, Altman DG, Campbell WB et al (2009) No surgical innovation without evaluation: the IDEAL recommendations. Lancet 26:1105-1112

4. Atallah S, Parra-Davila E, DeBeche-Adams T, Albert M, Larach S (2012) Excision of a rectal neoplasm using robotic transanal surgery (RTS): a description of the technique. Tech Coloproctol 16:389-392

5. Hompes R, Ris F, Cunningham C, Mortensen NJ, Cahill RA (2012) Transanal glove port is a safe and cost-effective alternative for transanal endoscopic microsurgery. Br J Surg 99:1429-1435

6. Kwon S, Billingham R, Farrokhi E et al (2012) Adoption of laparoscopy for elective colorectal resection: a report from the Surgical Care and Outcomes Assessment Program. J Am Coll Surg 214:909.e1-918.e1

7. Menon M, Sood A, Bhandari M et al (2014) Robotic kidney transplantation with regional hypothermia: a step-by-step description of the Vattikuti Urology Institute-Medanta technique (IDEAL phase 2a). Eur Urol 65:991-1000 